\title{
A GIS-based system for allocating municipal solid waste incinerator compensatory fund
}

\author{
Pei-Te Chiueh $^{\mathrm{a}, \mathrm{b}, *}$, Shang-Lien Lo ${ }^{\mathrm{a}, \mathrm{c}}$, Chia-Ling Chang ${ }^{\mathrm{a}, \mathrm{d}}$ \\ ${ }^{a}$ Research Center for Environmental Pollution Prevention and Control Technology, National Taiwan University, 71, Chou-Shan Road, \\ Taipei 106, Taiwan, ROC \\ ${ }^{\mathrm{b}}$ Department of Environmental Management, Tung Nan University, No. 152, Section 3, Peishen Road, Shen Keng, Taipei 222, Taiwan, ROC \\ ${ }^{\mathrm{c}}$ Graduate Institute of Environmental Engineering, National Taiwan University, 71, Chou-Shan Road, Taipei 106, Taiwan, ROC \\ ${ }^{\mathrm{d}}$ Department of Water Resources Engineering and Conservation, Feng Chia University, No. 100, Wenhwa Rd., Seatwen, Taichung 407,
} Taiwan, $R O C$

Accepted 13 January 2008

Available online 4 March 2008

\begin{abstract}
To ease the NIMBY (not in my back yard) syndrome of constructing municipal solid waste (MSW) incinerators in Taiwan, compensatory funding is widely allocated to the impacted communities to gain the acceptance and support of residents living the impacted areas. This paper presents a spatial methodology for distributing a compensatory fund more logically based on the environmental impact on each neighborhood in Taipei City. This method integrates ten impact factors, which have been proposed by a local committee, to evaluate all neighborhoods using mathematical models combined with spatial analyses in an analytic hierarchy process. The compensatory fund is distributed according to the resulting final scores. A GIS (geographic information systems)-based system has been developed to assist in assigning the final scores to the neighborhoods impacted. Results on impact factors and fund distributions are combined; they are included in an information system and displayed in spatial scales. For Taipei City, the impact of air quality during the incinerator operating period is the item of greatest concern to the surrounding residents and thus, it receives a relatively higher weight of 0.2894 . As a result, high impact scores were assigned to not only those neighborhoods hosting the incinerators, but also the neighborhoods where the maximum particulate air pollutants occurred. This approach could be applicable to other MSW incinerators with similar environmental impact problems and interest in compensation schemes.
\end{abstract}

(C) 2008 Elsevier Ltd. All rights reserved.

\section{Introduction}

Municipal solid waste (MSW) incinerators are generally considered to be undesirable infrastructures, because they cause air pollution problems and other adverse environmental impacts to the surrounding areas. In addition to maintaining strict emission standards to alleviate the environmental pollution, the authority may offer compensatory

\footnotetext{
* Corresponding author. Address: Department of Environmental Management, Tung Nan University, No. 152, Section 3, Peishen Road, Shen Keng, Taipei 222, Taiwan, ROC. Tel.: +886 2 86625935x405; fax: +886 2 86625934.

E-mail address: ptchueh@mail.tnu.edu.tw (P.-T. Chiueh).
}

funds to the communities impacted by incinerators to obtain the acceptance of residents. In fact, providing the host community with adequate compensation has even been identified as one of the factors contributing to the success of siting waste treatment facilities (Minehart and Zvi$\mathrm{ka}, 2002)$. The compensatory funding system is a popular approach in Taiwan as a tool of environmental justice to support the construction and operation of regional MSW incinerators. The spirit of a compensatory fund is based on the concept of recovering the welfare loss for the communities in the proximity of an undesirable facility. Therefore, distribution of the fund would be mainly carried out in accordance with the impact caused by MSW incinerators on specific areas (Hsu, 2006; Taiwan EPA, 1999). 
In Taiwan, all MSW incinerators must pass an Environmental Impact Assessment (EIA) before they are licensed to start the construction. Although the EIA report may consider all potential impacts of constructing and operating an incinerator on the surrounding environment, the predictions may not reflect the actual impacts. The environmental quality and conditions of the surrounding areas may be adversely impacted by MSW incinerator operations. A number of studies have been conducted to evaluate the actual impact of MSW incinerator operations on the surrounding environment. For example, Morselli et al. $(2002,2005)$ pointed out that the heavy metals observed in the atmospheric wet and dry depositions significantly depended on distance from incinerator. Valberg et al. (1996) evaluated the health impact of MSW incinerators by considering the direct and indirect exposure pathways of various metals and organic compounds, and concluded that MSW incinerator emissions do not contribute measurably to population health risks.

Spatially variable correlations between emissions and effects are crucial to analyses of scenarios of fund distribution. Chang and Chang (2000) have proposed an assessment framework for two neighboring towns located around a MSW incinerator in Taipei County. They utilized the analytic hierarchy process (AHP) to integrate major environmental impacts caused by a MSW incinerator, and considered relative effects on two neighboring towns, but further spatial analysis was not considered in their study.

A geographic information system (GIS) has adequate functionalities to capture, store, check, manipulate and process spatially referenced data. Furthermore, GIS is often applied as the integrating framework for spatial analysis and modeling (Dai and Rocke, 2000). Sharholy et al. (2006) reported the use of GIS generated maps to characterize and manage MSW. Kontos et al. (2005) described a MSW landfill siting methodology utilizing the combined GIS and AHP method. While much work has been devoted to specific pollutant impacts in different waste management scenarios using GIS, no studies have applied the integrated results to determine the allocation of MSW incinerator compensatory funds.

\section{Background information}

Taipei City is located in northern Taiwan, with longitudes between $121^{\circ} 27^{\prime} \mathrm{E}$ and $121^{\circ} 39^{\prime} \mathrm{E}$ and latitudes between $24^{\circ} 28^{\prime} \mathrm{N}$ and $25^{\circ} 13^{\prime} \mathrm{N}$ (Fig. 1). The $272 \mathrm{~km}^{2}$ city is situated in a basin, which is surrounded by a mountain range of approximately $1000 \mathrm{~m}$. Being a highly developed area, Taipei has 2.6 million residents or nearly $12 \%$ of the total population in Taiwan. With regard to the administrative divisions, the city is divided into 12 districts that are subdivided into a total of 449 "neighborhoods". The "neighborhood" is a basic administrative unit but will also

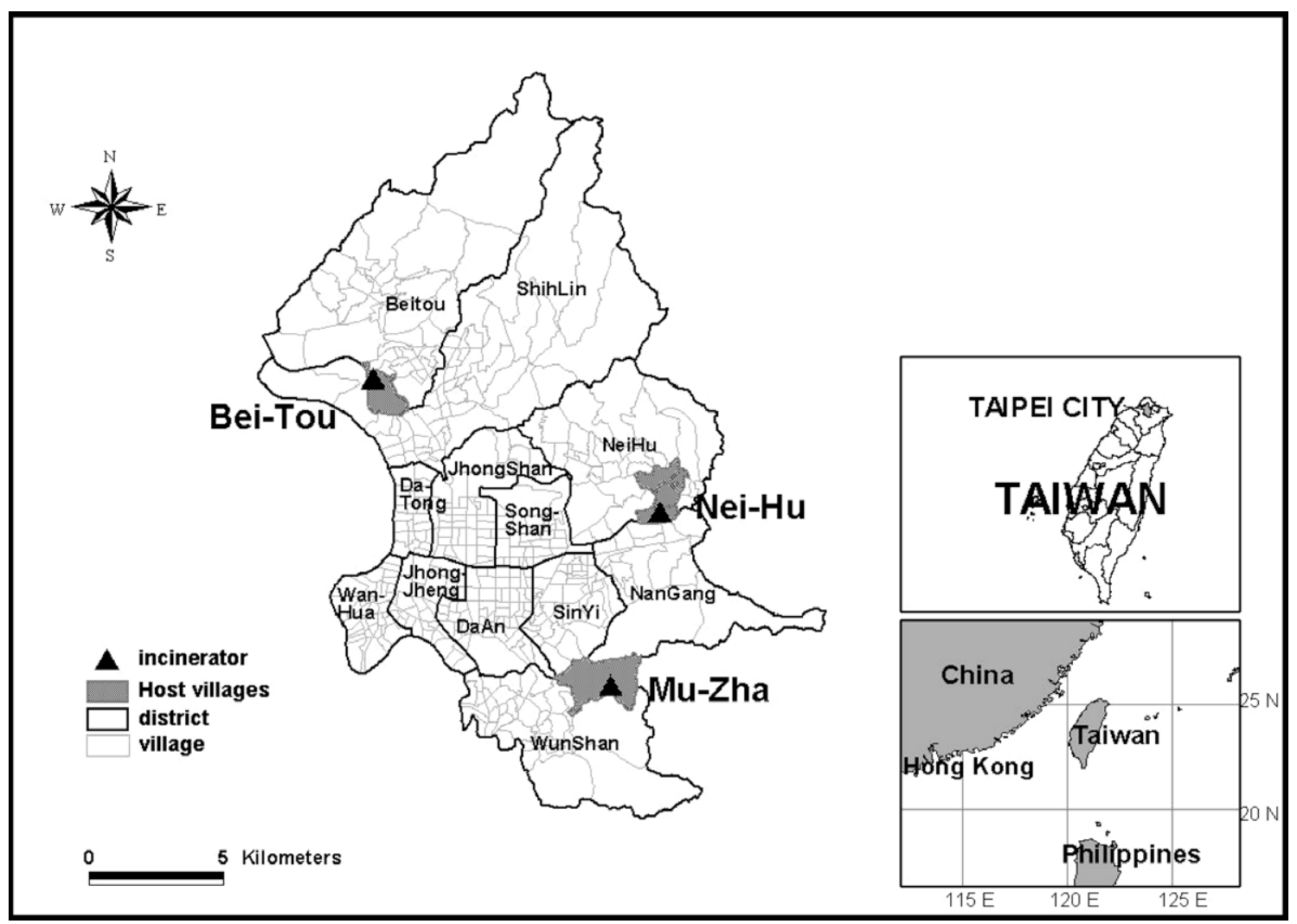

Fig. 1. The study area. 
be used as the spatial unit for evaluating the environmental impact and distributing compensatory funds in this study.

For many years, Taipei has maintained a solid waste management policy that favors incineration over landfilling for municipal waste disposal. Thus, three incineration plants, Nei-Hu, Mu-Zha and Bei-Tou, were constructed in 1992, 1995, and 1999, respectively. The installed daily incineration capacities are 900 tons $(300$ Tons $\times 3)$ for Nei-Hu, 1500 Tons $(375$ Tons $\times 4$ ) for Mu-Zha, and 1800 Tons $(450$ Tons $\times 4)$ for Bei-Tou. Including some general industrial wastes, the actual average daily quantities of solid wastes incinerated are 262, 633, and 946 Tons for the three respective incinerators. All these incinerators have a mechanical grate system, operate in continuous mode, and recover heat energy which is converted into electricity. The waste flue-gas is treated with semi-dry scrubbers and bag-filters in Nei-Hu and Bei-Tou plants, as well as electronic precipitator and wet scrubber in $\mathrm{Mu}$ Zha plant (TDEP, 2003).

For compensating the local communities around the incinerators, a statute was adopted in 1994 that specifies the target area, application regulations, and distribution method of the compensatory fund. Since the distribution method only considered the populations and the waste quantities generated by the 12 districts, it drew criticisms and disputes about its fairness between neighborhoods within a district. Some districts are so large that several neighborhoods in these districts may realize different levels of impacts from the incinerators. The statute was revised in 2000 to stipulate that the fund distribution be based on the degree of impact suffered by each neighborhood (TDEP, 2003). According to the revised statute, $20 \%$ of the compensatory fund should be reserved for the host neighborhoods, where the incinerators are located; the remaining $80 \%$ is allocated to nearby neighborhoods based on the impacts they receive.

The compensatory fund allotted to the nearby neighborhoods of the three incinerators is about US $\$ 4.5$ million (in 2003 US dollars). It came from a fixed portion of the disposal tax and the revenue from selling electricity generated by MSW incinerators. The Mu-Zha Incineration Plant and the Bei-Tou Incineration Plant each have only one host neighborhood, while the Nei-Hu Incineration Plant has five host neighborhoods that are all close to it. Hence, before the incineration plants were constructed, the authority had coordinated with local residents to list all seven neighborhoods as the host area (Fig. 1).

\section{Methodology}

The proposed GIS-based model for fund allocation involves the assessment and integration of environmental impacts. An information system has been developed in ESRI Avenue ${ }^{\circledR}$ scripts and ArcView ${ }^{\circledR} 3.3$ GIS software to support the process of making the composite evaluation criteria, performing the multiple criteria analyses and carrying out the fund distribution alternatives.

\subsection{Evaluating environmental impacts}

The problem of evaluating environmental impacts associated with MSW incineration was structured by extracting key factors from the items related to incinerator construction and operation. Specific items for mitigating the adverse impacts as mentioned in the incinerators' EIA reports were carefully investigated. The evaluating structure has been adjusted through frequent communications with local residents and examination committees such that public concerns over the impact of incinerators on their intrinsic properties and external environment would be addressed. The structure was decomposed into three levels according to their characteristics to formulate a hierarchical model as shown in Fig. 2. The topmost level is the focus of the goal, i.e., the distribution approach of the compensatory fund. The intermediate level corresponds to the major categories of impact, namely the construction impacts of incinerators, operation impacts of incinerators, transportation impacts of the MSW collection vehicles and the population of each neighborhood. The lowest hierarchical level represents ten impact factors to be evaluated on different scales as will be illustrated in later sections.

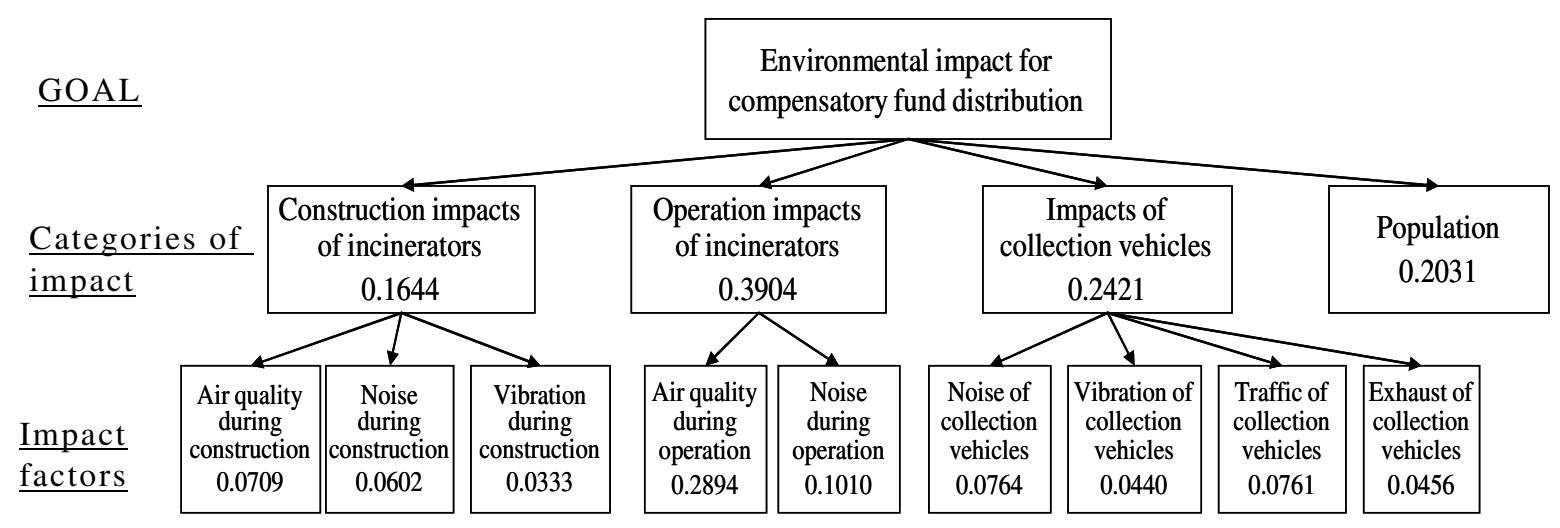

Fig. 2. AHP model for evaluating environmental impact for compensatory fund of municipal solid waste incinerators. 


\subsubsection{Construction impacts of incinerators}

While the three incinerators had already been operated for some time, the construction impacts were still considered in this research. Three factors (Table 1) were selected to characterize the impacts during the construction period of incinerators; they were the increment of concentration of air pollutants, noise $(N)$ and vibration $(V)$.

For air pollution, the ISC3 (USEPA, 2005) model was used to simulate the dispersion of pollutants emitted during the construction period. Only the total suspended particle (TSP) was treated as a major pollutant, and an emission rate of $4.86 \times 10^{-4} \mathrm{~g} / \mathrm{m}^{2} / \mathrm{s}$ was assumed for the construction area. The evaluation was carried out for the impacted neighborhoods within a radius of $4 \mathrm{~km}$ from the center of the incinerator.

The noise impact was predicted and analyzed using the SoundPLAN model (SoundPLAN, 2005), which considered each noise source from point, line, and area and their combined noise levels. In this analysis, the minimum sensible threshold of noise was set to be $45 \mathrm{~dB}(\mathrm{~A})$ with a $5 \mathrm{~dB}(\mathrm{~A})$ increment between two levels. The grading standard was based on the fading distance and affected area of maximum noise level calculated using the noise model.

This study only relied on empirical rules to evaluate vibration because no applicable and approved formula has been proposed for the diverse construction media. The minimum threshold of vibration was set to be $40 \mathrm{~dB}$ with a $5 \mathrm{~dB}$ increment between a level and the next higher level. As a result of constructing impact, high grading values for these three factors rapidly diminishes for neighborhoods away from the construction site. Thus, only the incinerator host neighborhoods and a few nearby neighborhoods are affected, as shown in Fig. 3a-c.

\subsubsection{Operation impacts of incinerators}

The operation impact comprises two factors: air quality and noise. The ISC3 model, which is similar to the model used for evaluating the construction impacts, was applied to simulate the dispersion of pollutants emitted from incinerators. When the incinerators are put into operation, all neighborhoods in the whole Taipei city and nearby counties were evaluated because emission plumes from all three incinerators may affect these areas.

\section{Table 1}

Grading values for the construction impacts of incinerators

\begin{tabular}{llll}
\hline $\begin{array}{l}\text { Increment of TSP } A Q_{1} \\
\left(\mu \mathrm{g} / \mathrm{Nm}^{3}\right)\end{array}$ & $\begin{array}{l}\text { Noise } N_{1} \\
(\mathrm{~dB}(\mathrm{~A}))\end{array}$ & $\begin{array}{l}\text { Vibration } V_{1} \\
(\mathrm{~dB}(\mathrm{~A}))\end{array}$ & $\begin{array}{l}\text { Grading } \\
\text { value }\end{array}$ \\
\hline$A Q_{1}<0.5$ & $N_{1}<50$ & $V_{1}<40$ & 0 \\
$0.5 \leqq A Q_{1}<1$ & $50 \leqq N_{1}<55$ & $40 \leqq V_{1}<45$ & 1 \\
$1 \leqq A Q_{1}<2$ & $55 \leqq N_{1}<60$ & $45 \leqq V_{1}<50$ & 2 \\
$2 \leqq A Q_{1}<3$ & $60 \leqq N_{1}<65$ & $50 \leqq V_{1}<55$ & 3 \\
$3 \leqq A Q_{1}<5$ & $65 \leqq N_{1}<70$ & $55 \leqq V_{1}<60$ & 4 \\
$5 \leqq A Q_{1}<10$ & $70 \leqq N_{1}<75$ & $60 \leqq V_{1}<65$ & 5 \\
$10 \leqq A Q_{1}<20$ & $75 \leqq N_{1}<80$ & $65 \leqq V_{1}<70$ & 6 \\
$20 \leqq A Q_{1}<30$ & $80 \leqq N_{1}<85$ & $70 \leqq V_{1}<75$ & 7 \\
$30 \leqq A Q_{1}<40$ & $85 \leqq N_{1}<90$ & $75 \leqq V_{1}<80$ & 8 \\
$40 \leqq A Q_{1}$ & $90 \leqq N_{1}$ & $80 \leqq V_{1}$ & 9 \\
\hline
\end{tabular}

The modeling grid consisted of 2514 receptor points consisting of two sizes: $700 \mathrm{~m}$ by $700 \mathrm{~m}$ for regular areas and $300 \mathrm{~m}$ by $300 \mathrm{~m}$ for densely populated areas. The four major pollutants to be evaluated were sulfur dioxide $\left(\mathrm{SO}_{2}\right)$, nitrogen dioxide $\left(\mathrm{NO}_{2}\right)$, hydrogen chloride $(\mathrm{HCl})$ and TSP. Their emission rates for evaluation are based on design concentrations and capacities of the incinerators. The ISC3 Model was used to simulate the yearly average concentrations of these four air pollutants at receptor points. The GIS "points in polygon" function (ESRI, 1990) was used to distribute the ISC3 output to every neighborhood and calculate the neighborhood average. Five levels of even-number grading values were assigned to neighborhoods based on the increments of these four pollutants as shown in Table 2. The assigned values for these four pollutants were averaged and used as the final value for the impact factor of air quality for each neighborhood during MSW incinerator operation. The spatial result of this factor, shown in Fig. 4a, indicates that neighborhoods located in southwest Taipei had higher grading values. Additionally, the synthesized effects of these three incinerators were directly affected by the meteorological conditions of Taipei City, which is often under the influence of the East Asia monsoon season with prevailing northeasterly winds most the season.

Grading values for evaluating the noise impact caused by incinerator operation are carried out using the same method as for evaluating the construction impact (Table 1). The results show that only the host neighborhoods were affected, as demonstrated in Fig. 4b.

\subsubsection{Impacts of collection vehicles}

There are four impact factors considered for MSW collection vehicles: noise, vibration, traffic and exhaust. These factors should be evaluated in accordance with the MSW collection routes and route characteristics. The collection routes in all 12 districts were digitized into the GIS system for using "lines in polygon" analysis to calculate the distance in each neighborhood traveled by the MSW collection vehicles.

SoundPLAN, which is similar to the model used for evaluating construction and operation, was implemented to estimate the noise impact of MSW collection vehicles. The grading values of this factor were determined by considering the sum of background and vehicular noises, and the contribution of solely vehicular noise. The results were represented by a matrix as shown in Table 3 and Fig. 5a.

Evaluating vehicular vibration impact was based on empirical rules and the results of on-site noise analyses. The matrix similar to that for noise assessment was used for analyzing the synthetic effect of vibration as shown in Table 4 and Fig. 5b.

Based on GIS route analyses, the mileages traveled by MSW collection vehicles in each neighborhood were summed up to quantify the traffic impact. Moreover, the quantity of emission from collection vehicles was consid- 


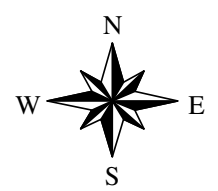

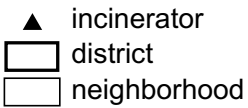
increment of air pollutant $0-2$

$2-4$

4-6

$6-8$

8-10

noise_construction

0-2

$2-4$

4-6

6-8

$8-10$

vibration_construction

$0-2$
$2-4$
$4-6$
$6-8$
$8-10$

$\begin{array}{llll}3 & 0 & 3 & \text { Kilometers }\end{array}$

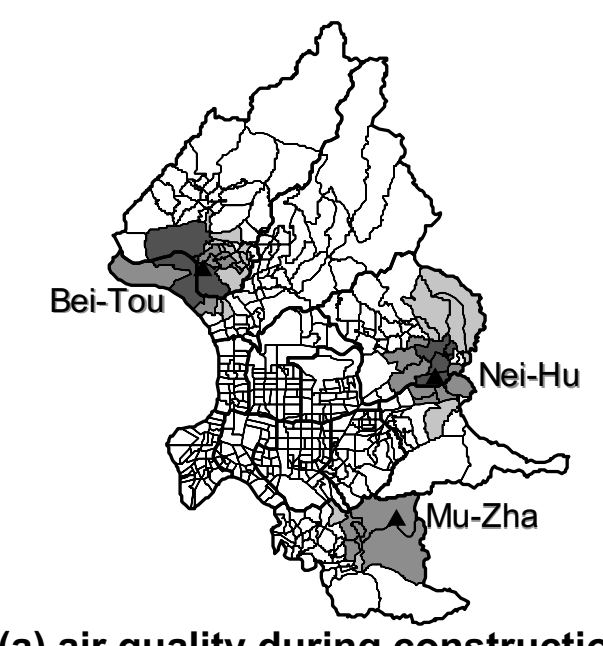

(a) air quality during construction

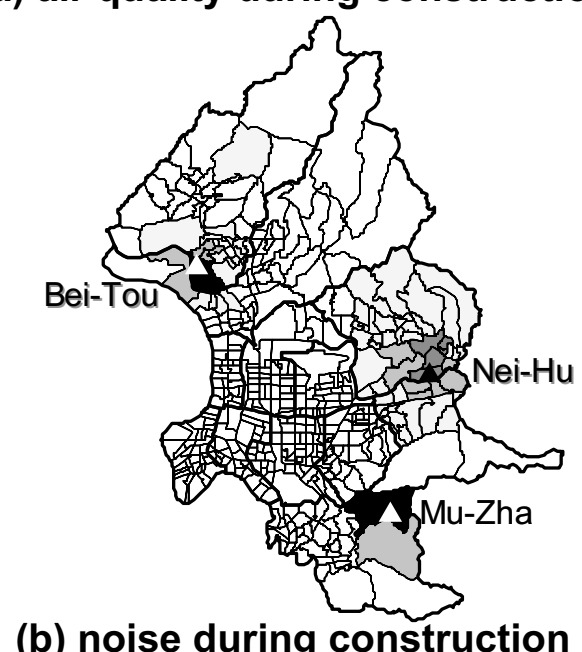

(b) noise during construction

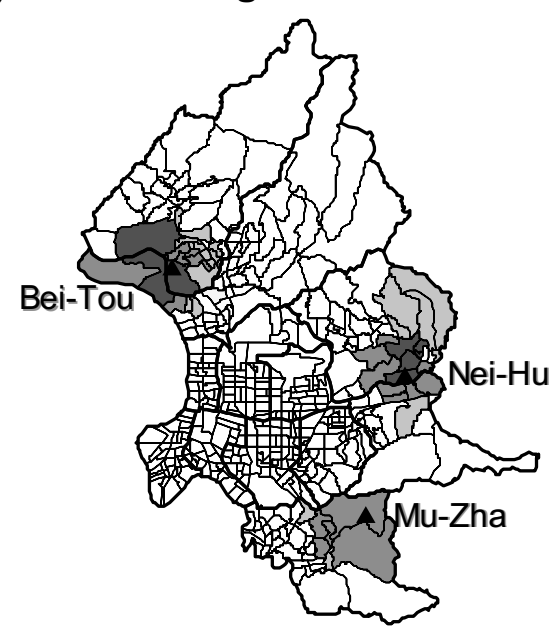

(c) vibration during construction

Fig. 3. Construction impacts of incinerators.

ered to be proportional to the distance traveled. Therefore, the grading values for traffic impacts were also used for evaluating vehicular emission as shown in Table 5 and Fig. 5c. In particular, most neighborhoods experiencing obvious increments in noise and vibration impact caused by the passing MSW collection vehicles is different from the observations for other factors. The impact factors for noise and vibration have a similar trend of spatial distribu- 
Table 2

Grading values for the impact of air quality operation of incinerators

Increment of air pollutants $\left(\mu \mathrm{g} / \mathrm{Nm}^{3}\right)$

\begin{tabular}{llll}
\hline $\mathrm{HC} 1\left(A Q_{2}\right)$ & $\mathrm{NO}_{2}\left(A Q_{3}\right)$ & $\mathrm{SO}_{2}\left(A Q_{4}\right)$ & $\mathrm{TSP}\left(A Q_{5}\right)$ \\
\hline$A Q_{2}<0.04$ & $A Q_{3}<0.16$ & $A Q_{4}<0.04$ & $A Q_{5}<0.032$ \\
$0.042 \leqq A Q_{2}<0.08$ & $0.162 \leqq A Q_{3}<0.32$ & $0.04 \leqq A Q_{4}<0.08$ & $0.032 \leqq A Q_{5}<0.064$ \\
$0.08 \leqq A Q_{2}<0.12$ & $0.322 \leqq A Q_{3}<0.48$ & $0.082 \leqq A Q_{4}<0.12$ & $0.064 \leqq A Q_{5}<0.096$ \\
$0.12 \leqq A Q_{2}<0.16$ & $0.48 \leqq A Q_{3}<0.64$ & $0.122 \leqq A Q_{4}<0.16$ & $0.096 \leqq A Q_{5}<0.128$ \\
$0.16 \leqq A Q_{2}$ & $0.64 \leqq A Q_{3}$ & $0.162 \leqq \mathrm{AQ}_{4}$ & $0.128 \leqq A Q_{5}$ \\
\hline
\end{tabular}

$0.162 \leqq \mathrm{AQ}_{4}$

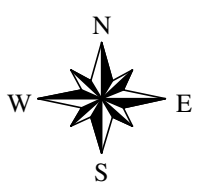

A incinerator

district

neighborhood

airquality_operation

$0-2$

$2-4$

4-6

$6-8$

8-10

noise_operation

\begin{tabular}{|c|}
\hline $0-2$ \\
\hline $2-4$ \\
$4-6$ \\
$6-8$ \\
\hline $8-10$
\end{tabular}

6

0

6 Kilometers

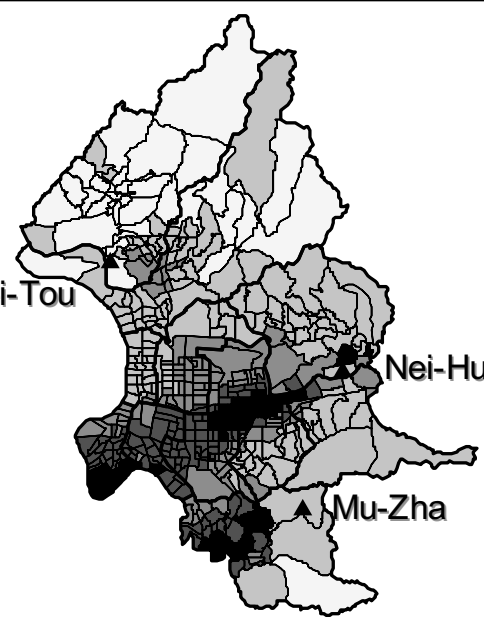

(a) air quality during operation

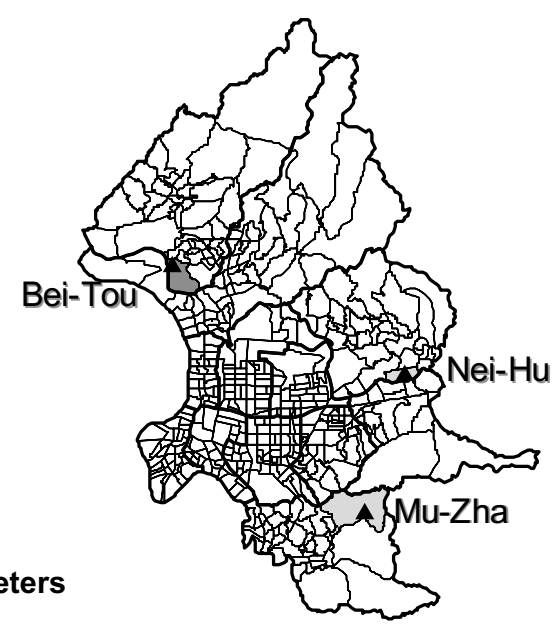

(b) noise during operation

Fig. 4. Operation impacts of incinerators.

Table 3

Grading values for the impact of noise of collection vehicles

Overall noise $N_{2}(\mathrm{~dB}(\mathrm{~A}))$

Grading value

Noise of collection vehicles $N_{3}(\mathrm{~dB}(\mathrm{~A}))$

\begin{tabular}{llllll} 
& $N_{3} \leqslant 60$ & $60<N_{3} \leqslant 65$ & $65<3_{2} \leqslant 70$ & $70<N_{3} \leqslant 75$ & $75<N_{3}$ \\
\hline$N_{2} \leqslant 75$ & 1 & 2 & 3 & 5 & 5 \\
$75<N_{2} \leqslant 80$ & 2 & 3 & 4 & 6 & 7 \\
$80<N_{2} \leqslant 85$ & 3 & 4 & 5 & 6 & 7 \\
$85<N_{2} \leqslant 90$ & 4 & 5 & 7 & 8 & 9 \\
$90<N_{2}$ & 5 & 6 & 7 & 9 \\
\hline
\end{tabular}




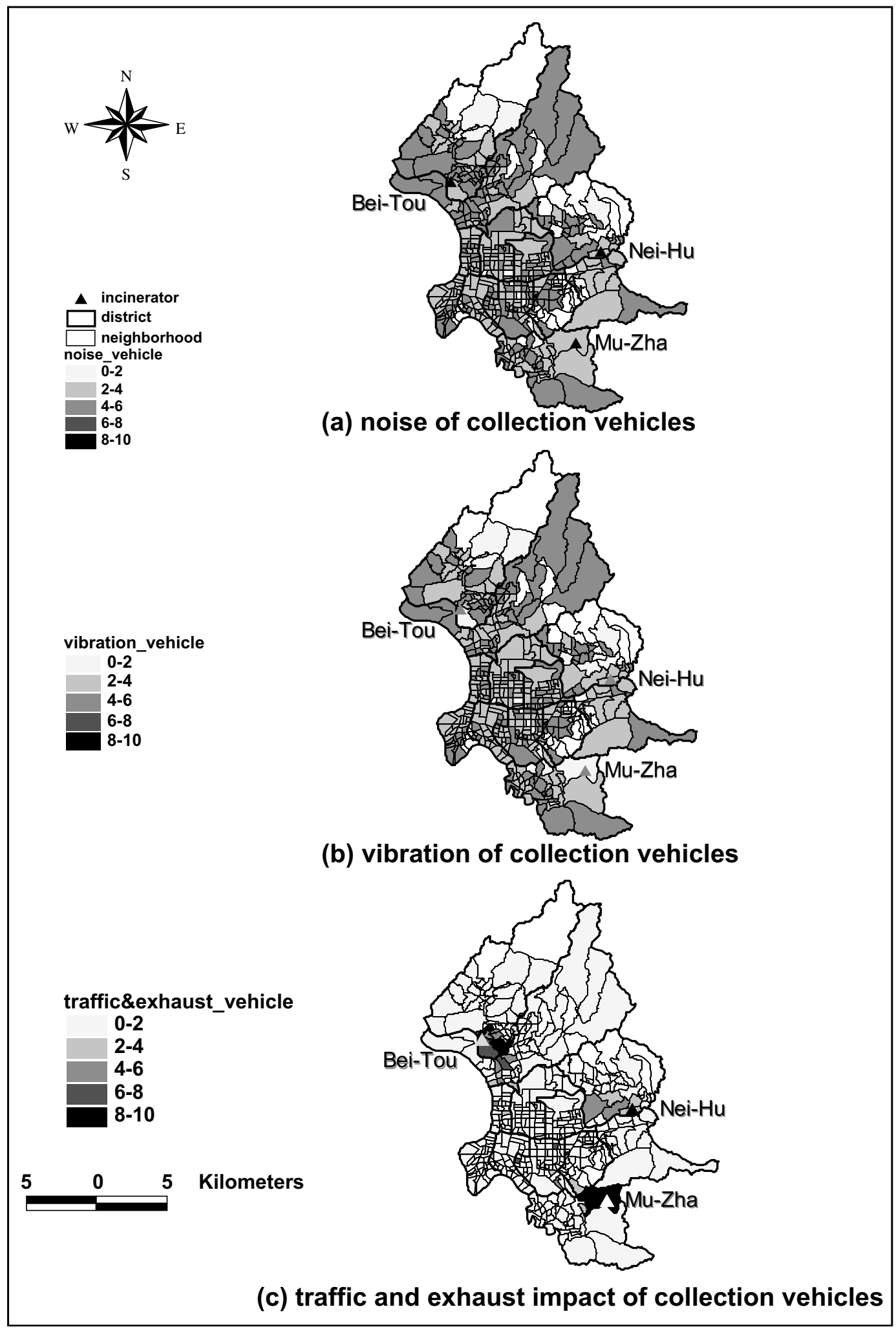

Fig. 5. Impacts of collection vehicles.

tion because they share the same database of collection routes and are analyzed using similar models (Fig. 5a and b). On the other hand, the traffic and exhaust impacts on neighborhoods were distributed more uniformly than other factors. Only a few neighborhoods near the incinerators received high grading values because they were on the main passing route of MSW collection vehicles as shown in Fig. 5c. 
Table 4

Grading values for the impact of vibration of collection vehicles

\begin{tabular}{|c|c|c|c|c|c|}
\hline \multirow{3}{*}{ Overall vibration $V_{2}(\mathrm{~dB}(\mathrm{~A}))$} & \multicolumn{5}{|c|}{ Grading value } \\
\hline & \multicolumn{5}{|c|}{ Vibration of collection vehicles $V_{3}(\mathrm{~dB}(\mathrm{~A}))$} \\
\hline & $V_{3} \leqslant 50$ & $50<V_{3} \leqslant 55$ & $55<V_{3} \leqslant 60$ & $60<V_{3} \leqslant 65$ & $65<V_{3}$ \\
\hline $65<V_{2} \leqslant 70$ & 2 & 3 & 4 & 5 & 6 \\
\hline $70<V_{2} \leqslant 75$ & 3 & 4 & 5 & 6 & 7 \\
\hline $75<V_{2} \leqslant 80$ & 4 & 5 & 6 & 7 & 8 \\
\hline
\end{tabular}

Table 5

Grading values for the impact of traffic and exhaust of collection vehicles

\begin{tabular}{ll}
\hline Travel distance $\times 10^{-4}, T\left(\mathrm{VK} 1 \times 10^{-4}\right)$ & Grading value \\
\hline$T=0$ & 0 \\
$0 \leqq T<1$ & 1 \\
$1 \leqq T<3$ & 2 \\
$3 \leqq T<5$ & 3 \\
$5 \leqq T<7$ & 4 \\
$7 \leqq T<10$ & 5 \\
$10 \leqq T<15$ & 6 \\
$15 \leqq T<20$ & 7 \\
$20 \leqq T<25$ & 8 \\
$25 \leqq T$ & 9 \\
\hline
\end{tabular}

\subsubsection{The population of each neighborhood}

The number of residents living in each neighborhood was considered a significant factor. When more people in a neighborhood suffer the impacts from incinerators, the neighborhood as a whole should receive a higher share of the compensatory fund allocated for the whole affected area. Based on the population of each neighborhood, every increase of 2000 persons was used as an increment for the next higher level. The grading scale is from 1 to 10 , while neighborhoods of fewer than 2000 persons received the lowest grading (1 point) and the neighborhoods of more than 20,000 persons received the highest grading (10 points). Neighborhoods of intermediate residents were assigned intermediate grading scales proportional to the number of residents. The spatial result of the population factor for Taipei City is shown in Fig. 6.

\subsection{Integrating impacts}

The AHP method proposed by Satty (1980) is a widely accepted decision making tool; it is an effective approach to extract the relative weighting factor of evaluation criteria. A recent overview of the AHP decision-making model indicates that its hierarchical structures and weighting factor have proved to be versatile and mature for researchers and practitioners to carry out various multiple criteria decisions (Vaidya and Kumar, 2006). AHP has also been applied to integrate the various environmental impact aspects, including siting of waste treatment facilities and power plants (Ramanathan and Ganesh, 1994; Ramanathan, 2001; Kontos et al., 2005; Ma et al., 2005).

The respondents' preference to factors listed in the questionnaires was collected using the following procedures. The paired factors at one hierarchical level were compared with respect to specific elements contained in the immediate upper level. For example, the three impact factors, air quality, noise and vibration during construction, were compared pair by pair with respect to the category of construction impacts caused by incinerators. The consis-

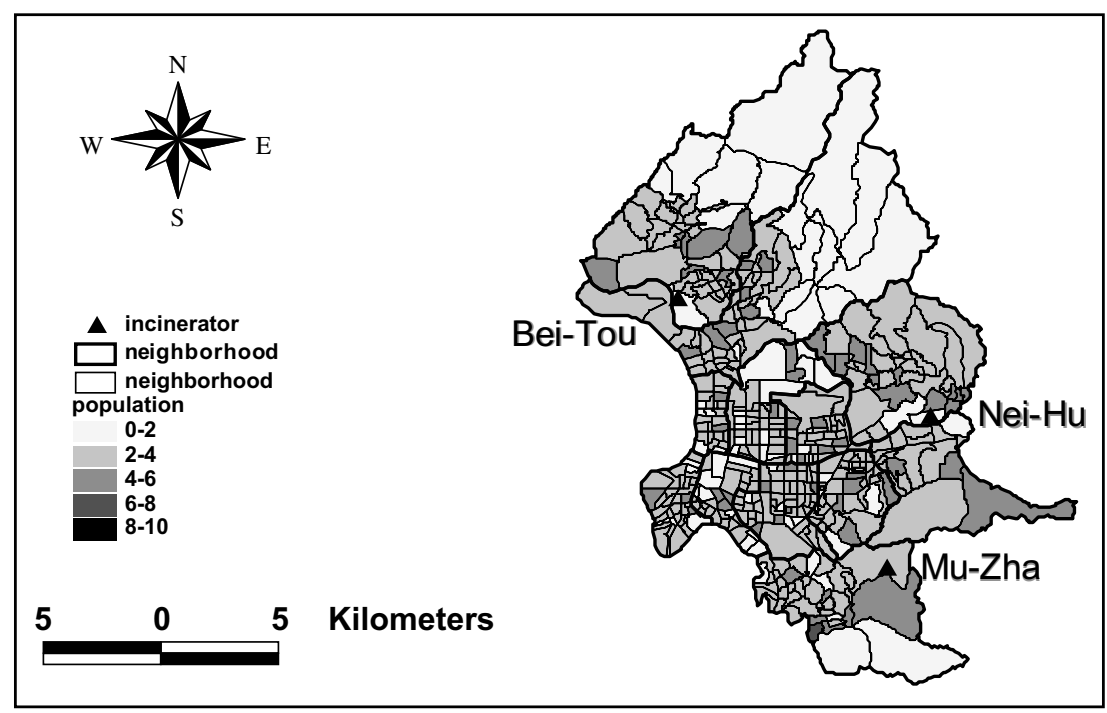

Fig. 6. Population impact. 
tency of the judgmental matrix can be determined based on a measure called "consistency ratio". In general, a consistency ratio of 0.10 or less is considered acceptable (Ramanathan, 2001; Brent et al., 2007). Once all comparisons of paired factors were carried out at every level and were proved to be consistent, the judgments could then be synthesized to obtain the relative weight of each factor. The operation of consistency verification is helpful to measure the degree of consistency among the comparisons of paired factors; this feature is regarded as one of the most desired advantages of AHP (Ho, 2007).

The ten experts who were involved in the AHP of this study had been selected from the Commission of Environmental Impact Assessment of Taipei Bureau of Environmental Protection. The specialized fields of these experts include: transportation (1), air quality (1), noise and vibration (3), incineration plant operation (2) and environmental impact assessment (3). In this study, the results obtained by analyzing questionnaires led to a consistency ratio of 0.0746 that conforms to the limit of less than 0.10 . Fig. 2 shows the weighting factor of the factors in various classes.

Results of evaluating the weighting factors were reported by the ten experts participating in the AHP assessment and then approved without modification by the Evaluation Committee before being used in the subsequent evaluation. In Fig. 2, the category of the incinerator operation received the highest relative weight for the impact (0.3904). Among all factors, the air quality impact factor (0.2894) was the highest, indicating that gaseous emissions from the incinerators' stacks were perceived as a serious pollutant source. The impact of collection vehicles, which was characterized by noise, vibration, traffic and exhaust of collection vehicles, was also an important category in the evaluating framework (0.2421). All those four factors were relevant to the routes of collection vehicles. The population in each neighborhood was another major factor, as shown by a relatively high weight $(0.2031)$.

For data aggregation, summation of the 10 weighed scores was used as the final score of each neighborhood (Si):

$S_{i}=\sum_{j=1}^{10}\left(A_{i j} \times W_{j}\right)$

where $S_{i}$ is the final score of neighborhood $i ; A_{i j}$ is the grading value of impact factor $j$ of neighborhood $i ; W_{j}$ is the weight of impact factor $j$.

\subsection{Allocating funds for each neighborhood}

The distribution of the compensatory fund was carried out according to the final scores for neighborhoods $\left(S_{i}\right)$ derived from the aggregation of the AHP relative weights and grading values of impact factors. Of the compensatory fund, $20 \%$ had been reserved for paying the seven host neighborhoods, and the remaining fund was distributed to the other 442 neighborhoods. All neighborhoods receiving final scores less than 2 were eliminated from the compensatory list.

Distributing the fund according to individual impact scores would be tedious and complicate administrative procedures, and the difference between funds allocated to the top and the bottom categories was thought likely to lead to objections if funds were proportional to estimated impacts. Hence, the Evaluation Committee with members representing the general public suggested that the neighborhoods be divided into five classes according the degree of impact. It was also agreed that the middle class of the five would receive the average percentage of the available fund, the upper two classes would receive $20 \%$ and $40 \%$ more than the average percentage, while the lower two classes would receive $20 \%$ and $40 \%$ less than the average percentage.

\section{Results and discussion}

The final scores, which were calculated by evaluating, weighing and aggregating the environmental impacts for the 449 neighborhoods in Taipei City, range from 0.78 to 5.57 (Fig. 7). The spatial distribution of scores from high to low is generally inversely proportional to the distance from incinerators. The host neighborhoods of incinerators have a higher average score of 3.65 (ranging from 2.50 to 5.57, see Fig. 7); it conforms to the public's cognition of perceiving the incinerator as the major cause of most environmental impacts. However, some distant neighborhoods far from the incinerators, located in southwest Taipei City, also receive high impact scores. Comparison of the spatial distribution of the ten impact factors, the impact of air quality during the incinerator operation appears to be the primary cause while the noise and vibration of MSW collection vehicles may be of secondary importance (Figs. 3a, $4 a$ and $b$ ).

According to the final scores, there are 48 neighborhoods with scores less than 2 points so that they are eliminated from compensatory funding list. There are 394 neighborhoods remaining on the funding lists (Fig. 8). Except those adjacent to the incinerator host area, neighborhoods in southwest Taipei City are also classified as more seriously affected areas and should receive higher compensatory funds. Moreover, the trend of classification for allocating funds is highly consistent with the classification of neighborhoods based on air quality during incinerator operation.

As shown in Table 6, the number of neighborhoods in each funds class ranges from 77 to 80 , because some neighborhoods have the same score such that they must be placed in the same class. Each host neighborhood receives $2.86 \%$ of the total budgeted fund and the neighborhoods in class I-V share much less funding; the host neighborhoods would receive approximately $\$ 129,000$ each while the class V neighborhoods receive $\$ 12,600$ each (in 2003 US dollars). 


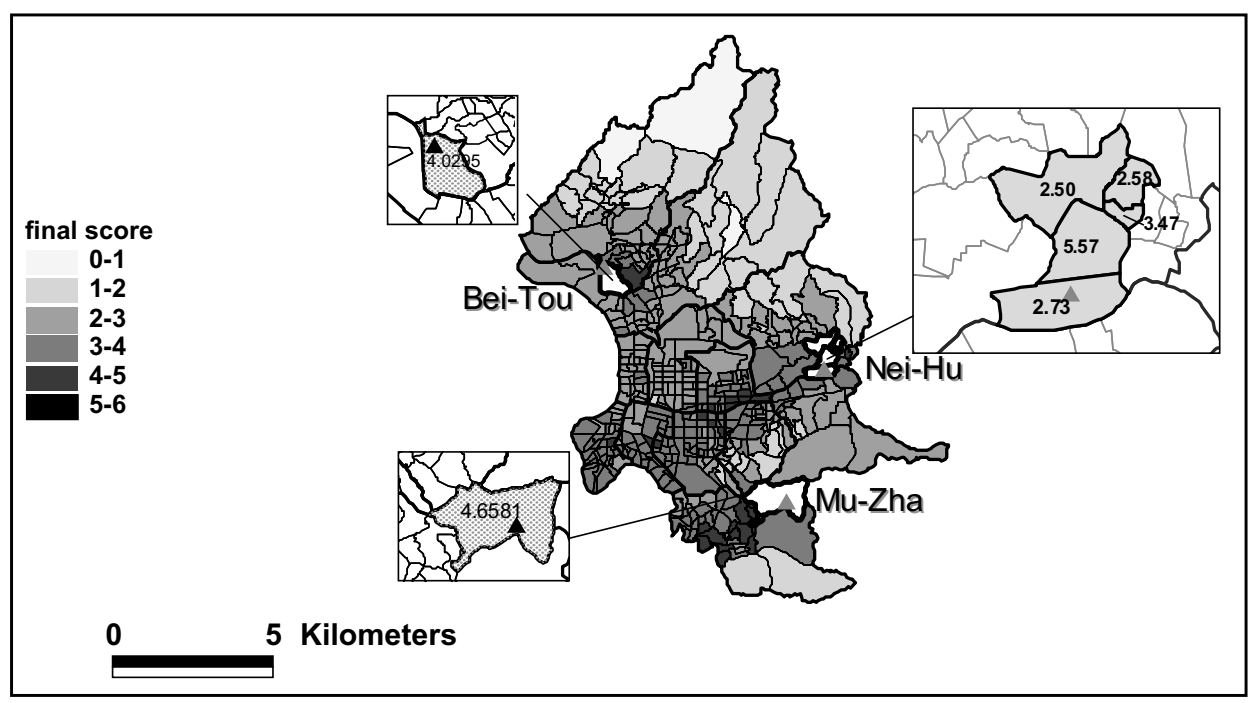

Fig. 7. Final score of each neighborhood.

The relative weight of an impact factor may affect the final score and the subsequent fund distribution for all neighborhoods. Fig. 9 demonstrates the sensitivity of the weights on final scores. If equal weight was adopted for each factor, the highly affected areas would always be centered on the incinerator or its vicinity. The extra weight on air pollution found through the AHP has led to the greater spread in weighted effects seen in Fig. 8.

In a previous study, Chang and Chang (2000) evaluated the influence of one incinerator on only two neighboring towns using EIA analyses. This study shows the potential to extend the EIA analysis to many more neighborhoods using GIS. In addition to its capabilities in processing, analyzing and modeling spatial data, GIS also provides good visualization tools that can be used effectively to present the impact evaluation results graphically.

A number of improvements are needed before the method used here could be considered a completely fair way to allocate funds. The method points to the importance of air pollution impacts, but does not consider real-time data of emissions from the incinerators or real-time monitoring stations in each neighborhood. In addition, the method uses a number of effects as a surrogate for human health impacts without directly examining the human health data. Finally, although the factors considered in the AHP framework have been hammered out through numerous discussions with local autonomous committees, other significant impacts, such

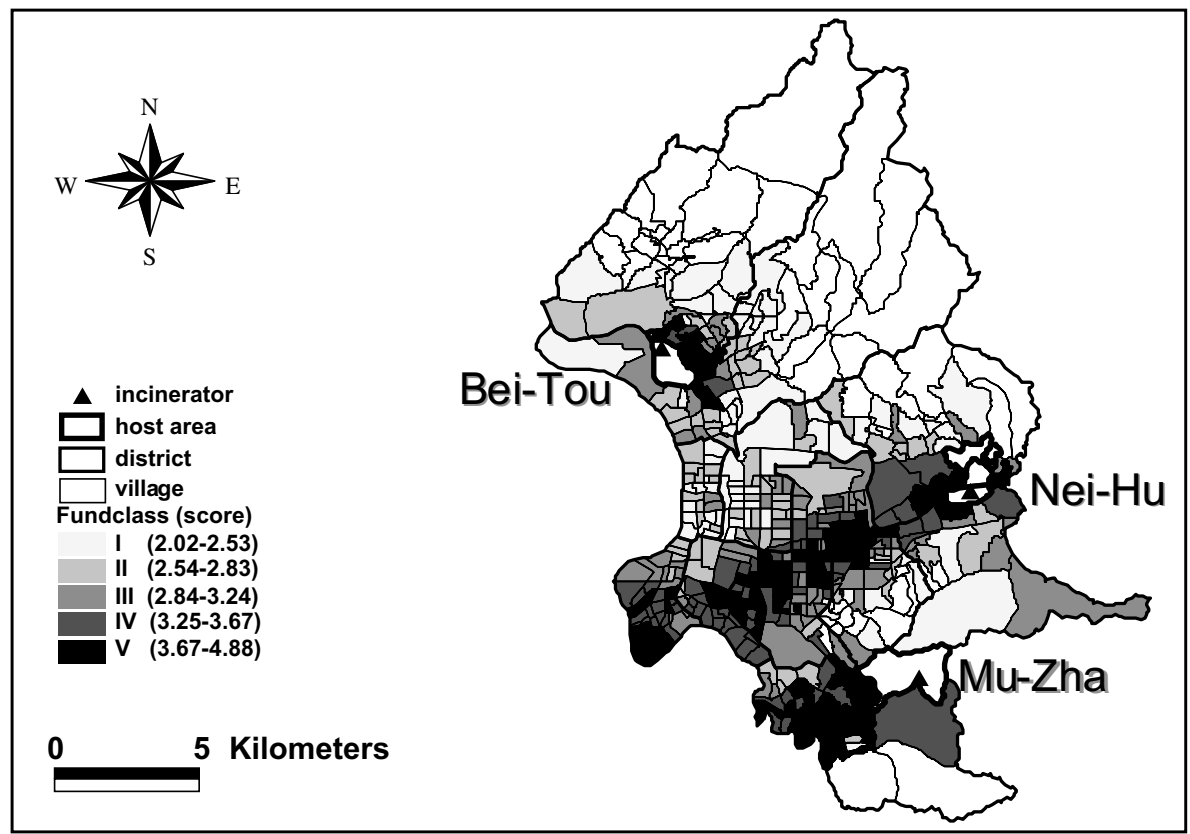

Fig. 8. Classification of compensatory fund distribution for MSW incinerators in Taipei City. 
Table 6

Payment scale of the compensatory fund distribution

\begin{tabular}{|c|c|c|c|c|}
\hline Class & $\begin{array}{l}\text { Number of } \\
\text { neighborhoods }\end{array}$ & Score range & Distribution criteria & $\begin{array}{l}\text { Percentage of total fund per } \\
\text { neighborhood }^{\text {c }}\end{array}$ \\
\hline I & 79 & $2.02-2.53$ & $60 \%$ of averaged fund ${ }^{a}$ & $0.12 \%{ }^{\mathrm{d}}$ \\
\hline II & 80 & $2.54-2.83$ & $80 \%$ of averaged fund & $0.16 \%$ \\
\hline III & 79 & $2.84-3.24$ & Averaged fund & $0.20 \%$ \\
\hline IV & 77 & $3.27-3.67$ & $120 \%$ of averaged fund & $0.24 \%$ \\
\hline \multirow[t]{2}{*}{$\mathrm{V}$} & 79 & $3.67-4.88$ & $140 \%$ of averaged fund & $0.28 \%$ \\
\hline & 394 (Sum) & 3.09 (Average) & & \\
\hline Host area & 7 & $\begin{array}{l}2.50-5.57(3.65 \\
\text { Average })\end{array}$ & $\begin{array}{l}\text { Shared out } 20 \% \text { of the total fund } \\
\text { equally }^{\text {b }}\end{array}$ & $2.86 \%$ \\
\hline Excluded & 39 & $0.78-2.00$ & None & 0 \\
\hline
\end{tabular}

a Averaged fund is equal to $(80 \%$ of the total fund $\div 394)$.

b $20 \%$ of the total fund was reserved for the 7 host neighborhoods in advance.

c Fund for each neighborhood in $\%$ of the total fund.

d For example, $0.12 \%$ of the total fund $=60 \% \times(80 \%$ of the total fund $\div 394)$.

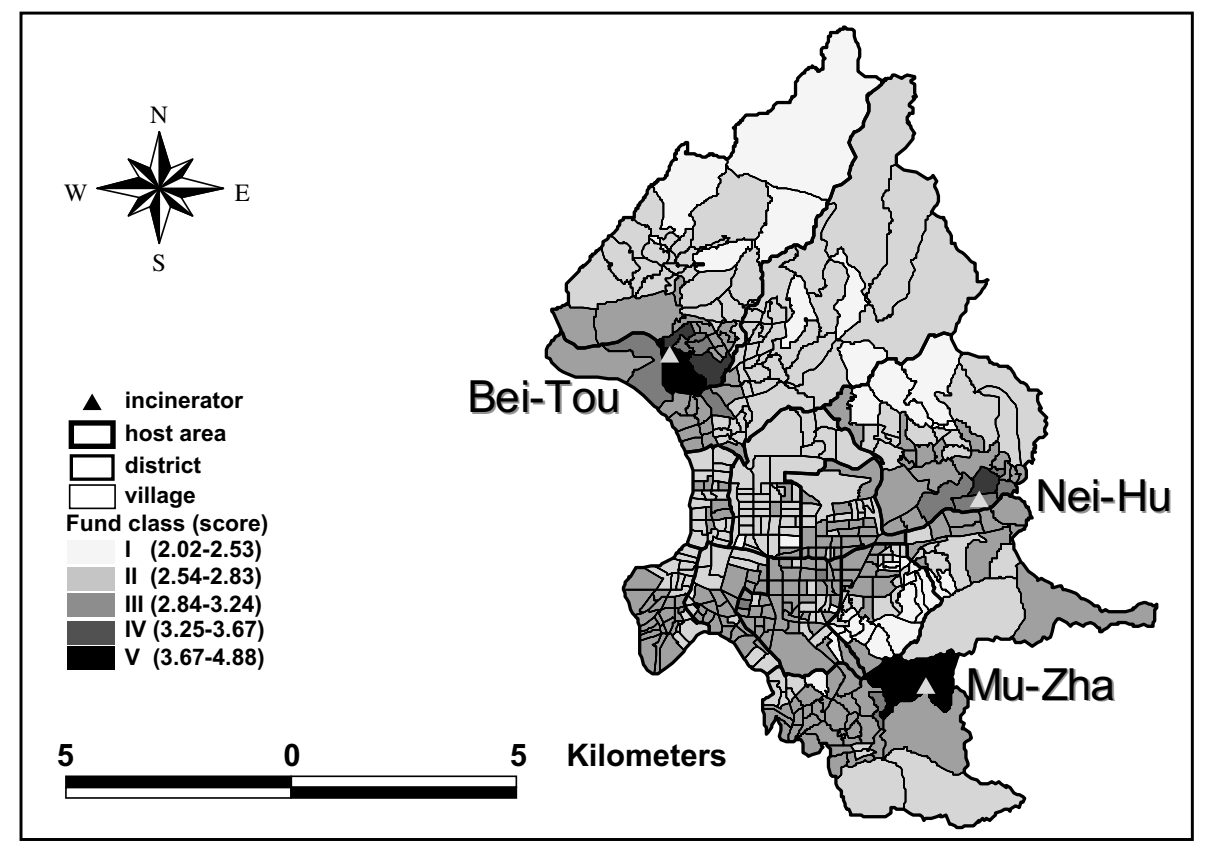

Fig. 9. Sensitivity analysis of impact factor weights (setting equal weight to each factor, 0.1).

as dioxin emission and the risk of ash treatment, were not included.

\section{References}

Brent, A.C., Rogers, D.E.C., Ramabitsa-Siimane, T.S.M., Rohwer, M.B., 2007. Application of the analytical hierarchy process to establish health care waste management systems that minimise infection risks in developing countries. European Journal of Operational Research 181 (1), 403-424.

Chang, N.B., Chang, Y.H., 2000. Assessing the redistribution strategy of the compensatory fund based on an integrated AHP and EIA approach for a municipal incinerator. In: Proceedings of the 2nd International Conference on Solid Waste Management, Taipei, Taiwan, ROC, pp. 175-190.

Dai, J., Rocke, D.M., 2000. A GIS-based approach to spatial allocation of area source solvent emissions. Environmental Modeling and Software 15, 293-302.
ESRI, 1990. Environmental System Research Institute, Inc., Understanding GIS, the ARC/INFO method.

Ho, W., 2007. Integrated analytic hierarchy process. European Journal of Operational Research. doi:10.1016/j.ejor.2007.01.00.

Hsu, S.H., 2006. NIMBY opposition and solid waste incinerator siting in democratizing Taiwan. The Social Science Journal 43, 453-459.

Kontos, T.D., Komilis, D.P., Halvadakis, C.P., 2005. Siting MSW landfills with a spatial multiple criteria analysis methodology. Waste Management 25, 818-832.

Ma, J., Scott, N.R., DeGloria, S.D., Lembo, A.J., 2005. Siting analysis of farm-based centralized anaerobic digester systems for distributed generation using GIS. Biomass and Bio-energy 28, 591-600.

Minehart, D., Zvika, N., 2002. Effective siting of waste treatment facilities. Journal of Environmental Economics and Management 43, 303-324.

Morselli, L., Bartoli, M., Brusori, B., Passarini, F., 2002. Application of an integrated environmental monitoring system to an incineration plant. The Science of the Total Environ 289 (1-3), 177-188. 
Morselli, L., Bartoli, M., Bertacchini, M., Brighetti, A., Luzi, J., Passarini, F., Masoni, P., 2005. Tools for evaluation of impact associated with MSW incineration: LCA and integrated environmental monitoring system. Waste Management 25, 191-196.

Ramanathan, R., Ganesh, L.S., 1994. Group preference aggregation methods employed in AHP: an evaluation and an intrinsic process for deriving members' weightages. Europe Journal of Operational Research 79, 249-265.

Ramanathan, R., 2001. A note on the use of the analytic hierarchy process for environmental impact assessment. Journal of Environmental Management 63, 27-35.

Satty, T.L., 1980. The analytic hierarchy process: planning. Priority Setting and Resource Allocation. McGraw-Hill, New York, USA.

Sharholy, M., Ahmad, K., Vaishya, R.C., Gupta, R.D., 2006. Municipal solid waste characteristics and management in Allahabad, India. Waste Management. Doi:10.1016/j.wasman.2006.03.0 01.
SoundPLAN, 2005. LLC Braunstein + Berndt GmbH, Tutorial SoundPLAN, Backnang, Germany. Available from: <http://www.soundplan.com/tutor.htm>.

Taiwan, EPA, 1999. Guidelines For Providing Compensatory Fund For Municipal Refuse Incinerator Operation, Taipei, Taiwan. Available from: <http://w3.epa.gov.tw/epalaw>.

TDEP, 2003. Department of Environmental Protection, Taipei City Government, Developing Environmental Impact Model for Municipal Solid Waste Incinerators in Taipei City, Final Report, Taipei, Taiwan. USEPA, 2005. User's Guide for the Industrial Source Complex (ISC3) Dispersion Models. Available from: < http://www.epa.gov/scram001/ userg/regmod/isc3v2.pdf>.

Vaidya, O.S., Kumar, S., 2006. Analytic hierarchy process: an overview of applications. Europe Journal of Operational Research 169, 1-29.

Valberg, P.A., Drivas, P.J., McCarthy, S., Watson, A.Y., 1996. Evaluating the health impacts of incinerator emissions. Journal of Hazardous Materials 47 (1-3), 205-227. 